\title{
A case of pathological fracture associated with chondroblastoma of the first metatarsal: natural development over 3 years
}

\author{
Shigeru Kobayashi $\cdot$ K. Takeno $\cdot$ K. Uchida $\cdot$ \\ T. Yayama $\cdot$ H. Nakajima $\cdot$ T. Miyazaki $\cdot$ H. Baba
}

Received: 9 September 2008 / Accepted: 15 October 2008 / Published online: 7 November 2008

(C) The Author(s) 2008. This article is published with open access at Springerlink.com

\begin{abstract}
Chondroblastoma of the metatarsal is a very rare condition. To our knowledge fewer than 20 cases have been reported in the world literature. We report a 34-yearold man with chondroblastoma of the first metatarsal. The clinical, radiological and pathological aspects of the tumor are discussed. On pathological examination, there were no typical findings suggestive of benign chondroblastoma such as chicken wire calcification. Therefore, it was difficult to determine whether the eosinophilic matrix observed in the stroma was osteoid or cartilaginous tissue, and differentiation from osteoblastoma was needed. However, the followup period of this patient was prolonged, and pain that was possibly due to pathologic fracture had occurred during this period, suggesting that these factors could have promoted fibrosis. The patient was treated by curettage and autologous bone grafting. At 4 years after surgery, there has been no evidence of recurrent tumor.
\end{abstract}

Keywords Chondroblastoma - Metatarsal · Pathological fracture $\cdot$ Surgery $\cdot$ Pathology

\section{Introduction}

Chondroblastoma was initially considered to be a variation of osteoclastoma. In 1942 Jaffe and Lichtenstein [9] reported that this is a chondrogenic tumor developing at the epiphysis of long bones and gave it the name of chondro-

S. Kobayashi $(\bowtie) \cdot$ K. Takeno $\cdot$ K. Uchida $\cdot$ T. Yayama .

H. Nakajima $\cdot$ T. Miyazaki $\cdot$ H. Baba

Department of Orthopedics and Rehabilitation Medicine,

Faculty of Medical Sciences, The University of Fukui,

23-3, Shimoaizuki, Matsuoka, Eiheiji, Fukui 910-1193, Japan

e-mail: kshigeru@u-fukui.ac.jp blastoma, which has been used ever since. This is a rare tumor that represents less than $1 \%$ of all primary tumors of bone [15]. The male:female ratio is about $2: 1$, so males are more frequently affected. The teens to twenties are the time of an increased incidence and young patients account for more than $80 \%$ of the total. Most patients complain of pain on movement or spontaneous pain. Chondroblastomas are typically developed at the epiphysis of long bones. We encountered a very rare case of benign chondroblastoma that developed at the epiphysis and extended to the proximal diaphysis of the first metatarsal. We report the clinical course of this case here with discussion of the relevant literature.

\section{Case report}

The patient was informed that data from the case would be submitted for publication and gave his consent. A 34-yearold healthy man presented with a 2 -week history of pain and swelling of his left great toe. There was no history of fever, chills, weight loss, or trauma, but he had a history of alcoholic liver disease. When he played volleyball, he developed pain in the left great toe and consulted a local doctor, who found a bone tumor of the first metatarsal on plain radiographs. He was referred to our hospital for further examination and treatment. However, he did not visit our hospital due to pressure of work until 3 years later, when he again had pain in the left great toe. Plain X-ray films taken at the first consultation showed a ground glasslike mass extending from the proximal part of the left first metatarsal with thinning of the cortex (Fig. 1a). Plain X-ray films taken at the present consultation showed extension of the tumor toward the metaphysis compared with the earlier films (Fig. 1b). Hematology tests and biochemistry tests 


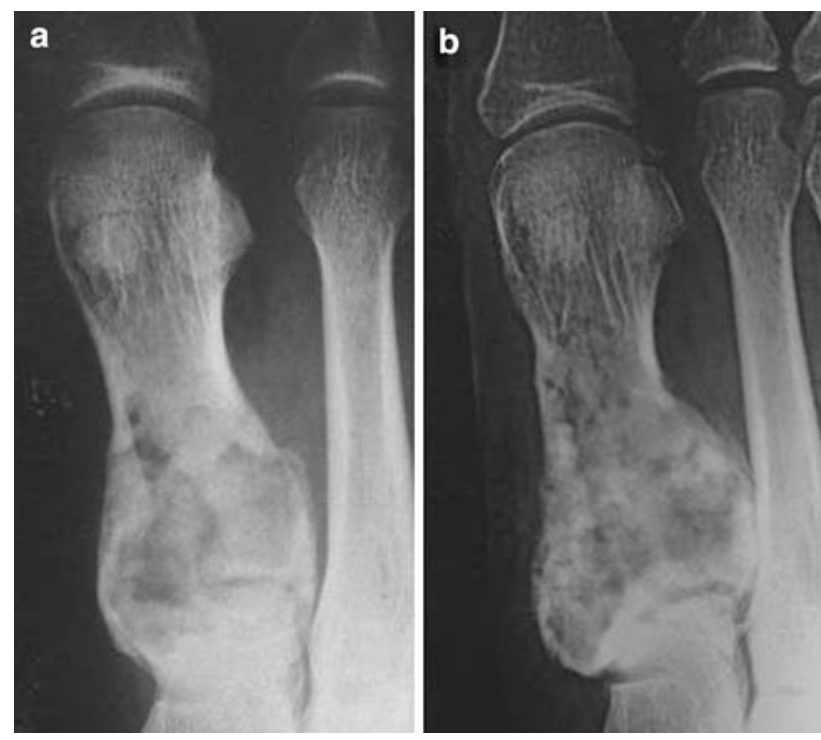

Fig. 1 Plane radiographs of the first metatarsal: $\mathbf{a}$ at the first consultation; $\mathbf{b}$ after 3 years of the first consultation revealed no abnormalities, except for mild hepatic dysfunction. MRI showed a low signal intensity on T1-weighted images and a mixture of high and low signal intensities on T2-weighted images, and enhanced MRI revealed marked enhancement of the whole tumor (Fig. 2). Bone scintigrams showed accumulation at the site of the tumor, but no accumulation in other areas (Fig. 3a). Angiography showed that the tumor was principally supplied via the dorsalis pedis artery and was densely stained (Fig. 3b, c). As the tumor was assumed to be benign bone neoplasm based on the clinical course, frozen section examination was performed to confirm its benign nature, followed by curettage, cryosurgery and autologous bone grafting from the ilium. Intraoperative findings showed that there was no obvious extraskeletal progression and that the lesion was filled with reddish-brown granulation-like tissue (Fig. 4). The tumor had was covered by bone cortex with well-preserved periosteum and showed solid medullary expansion inside the bone.
Fig. 2 Saggital MR imaging of the first metatarsal; a T1-weighted images (TR/TE: 500/35); b T1-weighted images after gadolinium injection $(0.1 \mathrm{mmol} / \mathrm{kg}) ; \mathbf{c}$ T2-weighted images (TR/TE: 2,000/100)
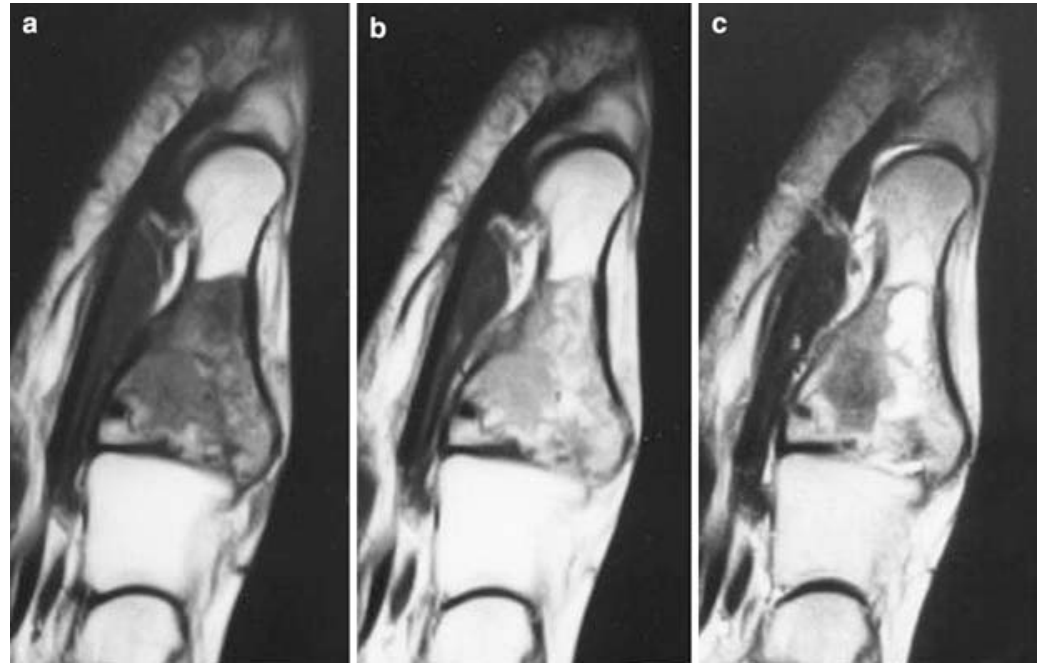

Fig. 3 Bone scintigram (a) and angiogram (b arterial phase, c venous phase)
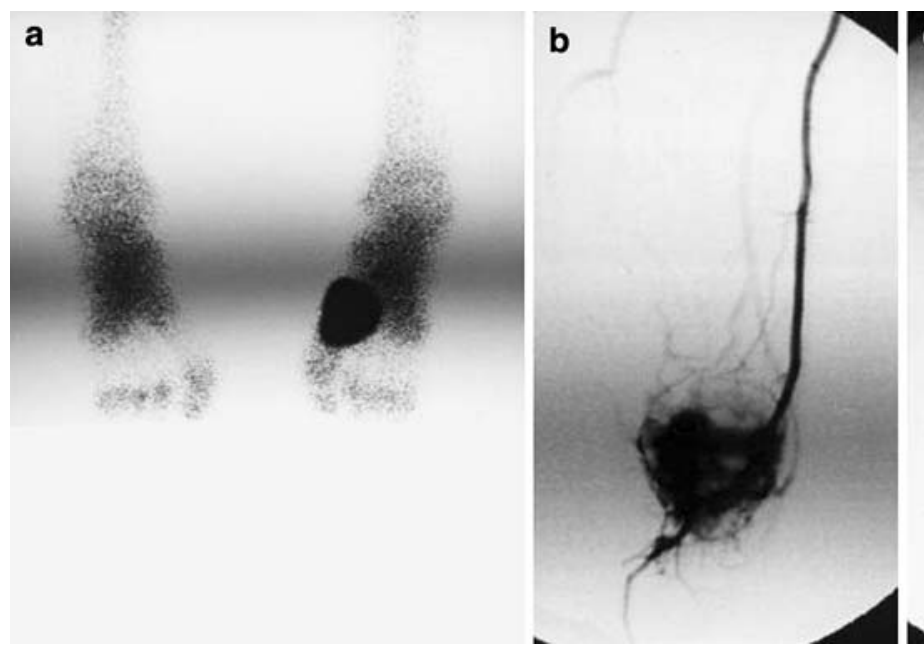


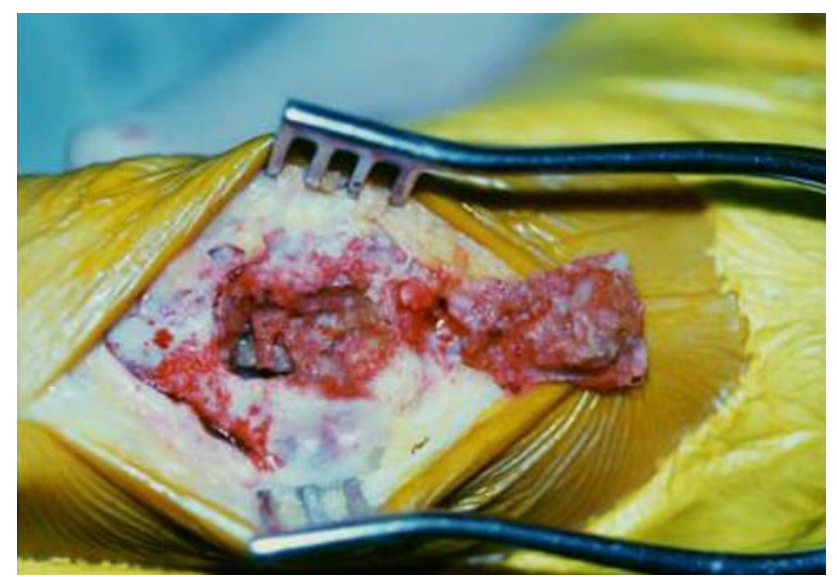

Fig. 4 Surgical findings. The tumor showed with reddish-brown granulation-like tissue

\section{Pathological findings}

Microscopy showed a dense arrangement of nearly round tumor cells containing nuclei with coffee bean-like notches, but no mitosis. The areas with evident calcify deposition had no chicken wire appearance, but consisted of densely accumulated tumor cells and lightly eosin-stained cartilage-like matrix with calcification. No hemorrhage or necrosis was detected (Fig. 5a, b). The stroma was lightly stained by Alcian blue (Fig. 5c) and the majority of the stroma was stained by Azan-Mallory stain (Fig. 5d), while silver impregnation stain revealed reticular fibers in the tumor cells (Fig. 5e). From these findings, this tumor was diagnosed as a chondroblastoma with changes indicating on obsolete lesion.

\section{Discussion}

Chondroblastoma usually develops in long bones such as the femur, the humerus, and the tibia. Among 1,533 reported cases of chondroblastoma, $162(10.6 \%)$ had tumors at the foot, but the metatarsal was only affected in $17(1.1 \%)$ (Table 1) [3-6, 8, 10, 12-15]. On plain X-ray films, there is a round or nearly round tumor that is confined to the epiphysis and has a distinct border, although it is occasionally
Fig. 5 Photomicrograph of the tumor. a Hematoxylin-eosin $(\times 20$, bar $=500 \mu \mathrm{m})$, b Hematoxylin-eosin $(\times 200$, bar $=50 \mu \mathrm{m})$, c Alcian blue stain $(\times 200$, bar $=50 \mu \mathrm{m})$, d Azan-Mallory stain $(\times 200$, bar $=50 \mu \mathrm{m})$, e Silver impregnation stain $(\times 200$, bar $=50 \mu \mathrm{m})$
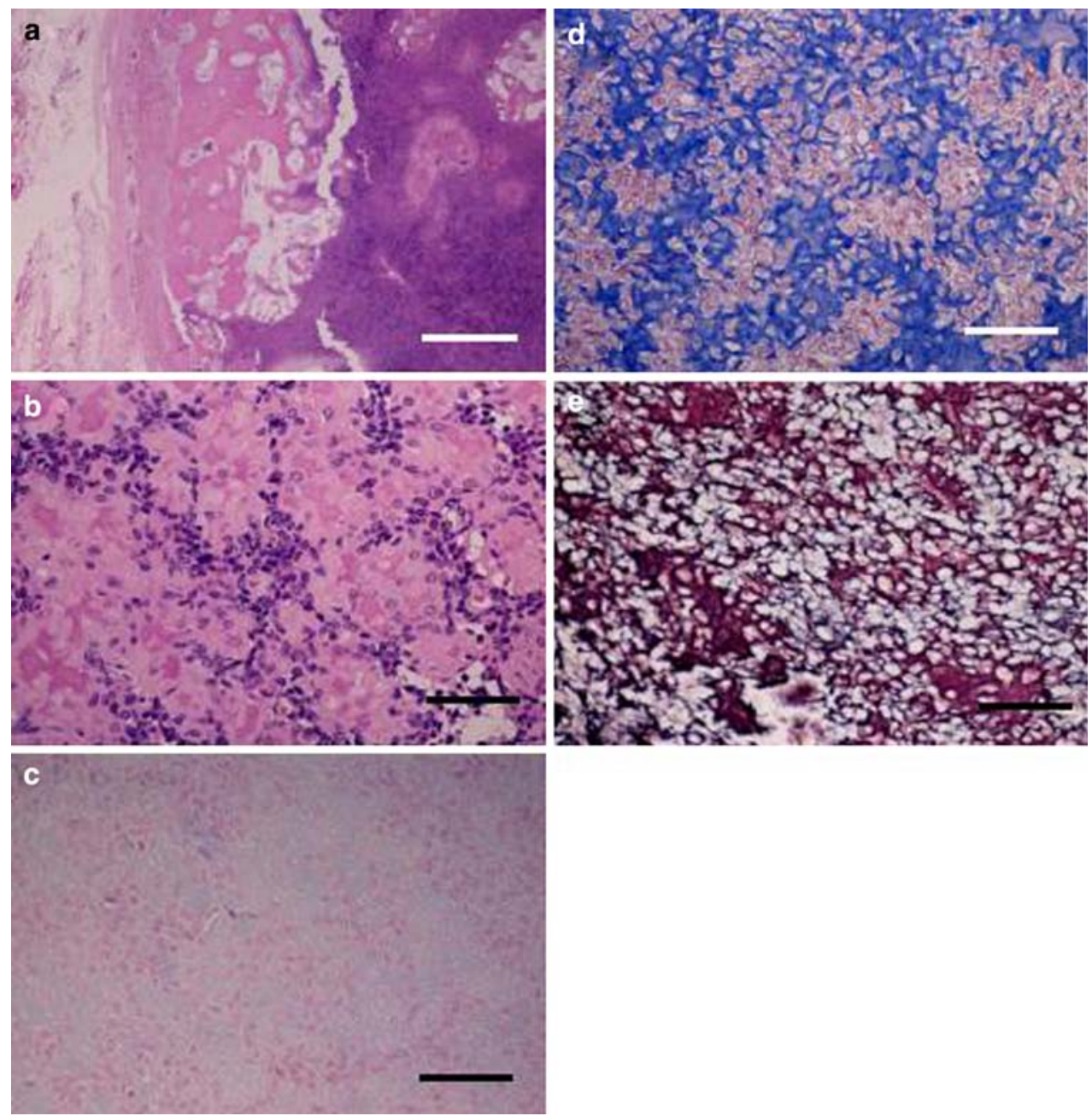
Table 1 Chondroblastoma of foot and metatarsal found in the literature

\begin{tabular}{llll}
\hline Literature source & Location & $\begin{array}{l}\text { Total number of } \\
\text { chondroblastoma }\end{array}$ \\
\cline { 2 - 3 } & $\begin{array}{l}\text { Metatarsal [number } \\
\text { of cases (\%)] }\end{array}$ & $\begin{array}{l}\text { Foot [number } \\
\text { of cases (\%)] }\end{array}$ & \\
\hline Schajowicz et al. [12] & $1(1.4 \%)$ & $11(15.9 \%)$ & 69 \\
Dahlin et al. [4] & $3(2.4 \%)$ & $17(13.6 \%)$ & 125 \\
Huvos et al. [9] & $10(2.2 \%)$ & $43(9.4 \%)$ & 458 (including those \\
McLeod et al. [10] & 0 & $8(11.1 \%)$ & 72 \\
Bloem et al. [3] & $1(1.0 \%)$ & $13(12.5 \%)$ & 104 \\
Springfield et al. [13] & 0 & $6(8.6 \%)$ & 70 \\
Turcotte et al. [14] & 0 & $3(4.3 \%)$ & 70 \\
Unni et al. [15] & 0 & $9(7.6 \%)$ & 119 \\
Fink et al. [6] & $1(0.3 \%)$ & $42(12.7 \%)$ & 332 \\
Davila et al. [5] & $3(1.4 \%)$ & $25(11.8 \%)$ & 211 \\
Atalar et al. [1] & $1(3.6 \%)$ & $2(7.1 \%)$ & 28 \\
Total number of cases & $17(1.1 \%)$ & $162(10.6 \%)$ & 1,533 \\
\hline
\end{tabular}

shown as a multilocular radiolucent lesion with irregular spotty calcification. This tumor generally occurs at the epiphyses of long bones, but it is known that the lesion is not necessarily confined to the epiphysis and occasionally extends to involve the methaphysis. Such extension of tumors developing in the long bones has been reported by Schajowics et al. [12] in 5 out of 46 cases, by Springfield et al. [13] in 5 out of 8 cases, and by Hudson et al. [7] in 2 out of 15 cases, so extension from the epiphysis to involve the metaphysis is not necessarily rare.

This tumor needs to be differentiated from malignant tumors, such as chondrosarcoma, clear cell chondrosarcoma and osteosarcoma; and from other benign lesions such as enchondroma, giant cell tumor, chondromyxoid fibroma, aneurysmal bone cyst, and osteoblastoma [2, 11, 12, 15]. Generally, chondroblastoma is composed of medium-sized, round or multinucleated cells with a distinct border, and the giant cells generally have several to more than ten small nuclei. In some cases, chondroid matrix is observed. In the present case, histopathological examination of an intraoperative specimen showed no typical findings suggestive of chondroblastoma, such as chicken wire calcification, possibly because it was an obsolete lesion. Therefore, it was difficult to determine whether the eosinophilic matrix observed in the stroma was osteoid or cartilaginous tissue, and differentiation from osteoblastoma was needed. However, the follow-up period of this patient was prolonged, and pain that was possibly due to pathologic fracture had occurred during this period, suggesting that these factors could have promoted fibrosis. The majority of the stroma was stained by Alcian blue and Azan-Mallory stains, while silver impregnation staining revealed reticular fibers in tumor cells. From these findings, this lesion was considered to have fibrotic chondroid stroma, and accordingly was diagnosed as a chondroblastoma. Treatment of chondroblastoma involves curettage of the lesion and bone grafting, in principle. The recurrence rate has been reported as $11-24 \%$, so it is not necessarily low [3, 4, 8, 12, 13]. For treatment of the present case, the lesion was accurately localized by CT and MRI, so that curettage could be adequately performed using a surgairtome as well as a chisel and a curette in order to prevent local recurrence. Cryosurgery was also performed to prevent recurrence. This procedure led to a large bone defect, but the defect was filled by using autologous bone grafts. Plain X-ray films taken 4 years postoperatively showed good bone union and no relapse of the tumor.

Conflict of interest statement No funds were received in support of this study.

Open Access This article is distributed under the terms of the Creative Commons Attribution Noncommercial License which permits any noncommercial use, distribution, and reproduction in any medium, provided the original author(s) and source are credited.

\section{References}

1. Atalar H, Basarir K, Yildiz Y, Erekul S, Salik Y (2007) Management of chondroblastoma: retrospective review of 28 patients. J Orthop Sci 12:334-340

2. Bakotic B, Huvos AG (2001) Tumors of the bones of the feet: the clinicopathologic features of 150 cases. J Foot Ankle Surg 40:277-286

3. Bloem JL, Mulder JD (1985) Chondroblastoma: a clinical and radiological study of 104 cases. Skeletal Radiol 14:1-9

4. Dahlin DC, Ovins JC (1972) Benign chondroblastoma. A study of 125 cases. Cancer 30:401-413

5. Davila JA, Amrami KK, Sundaram M, Adkins MC, Unni KK (2004) Chondroblastoma of the hands and feet. Skeletal Radiol 33:582-587 
6. Fink BR, Temple TH, Chiricosta FM, Mizel MS, Murphey MD (1997) Chondroblastoma of the foot. Foot Ankle Int 18:236242

7. Hudson TM, Hawkins IF (1981) Radiological evaluation of chondroblastoma. Radiology 139:1-10

8. Huvos AG, Marcove RC (1973) Chondroblastoma of bone: a critical review. Clin Orthop 95:300-312

9. Jaffe HL, Lichitenstein L (1942) Benign chondroblastoma of bone; an intepretation of the so called calcifying chondromatous giant cell tumor. Am J Pathol 8:969-991

10. McLeod RA, Beabout JW (1973) The roentgenographic features of chondroblastoma. J Roentgenol Radium Ther Nucl Med 118:464-471
11. Ostrowski ML, Spjut HJ (1997) Lesions of the bones of hands and feet. Am J Surg Pathol 21:676-690

12. Schajowics F, Gallardo H (1970) Epiphyseal chondroblastoma of bone: a clinico-pathological study of sixty nine cases. J Bone Joint Surg 52B:205-226

13. Springfield DS, Capanna R, Gherlinzoni F, Picci P, Campanacci M (1985) Chondroblastoma: a review of seventy cases. J Bone Joint Surg 67A:748-755

14. Turcotte RE, Kurt AM, Sim FH, Unni KK, Mcleod RA (1993) Chondroblastoma. Hum Pathol 24:944-949

15. Unni KK (1996) Benign chondroblastoma. In: Unni KK (ed) Bone tumors: general aspects and data on 11087 cases, 5th edn. Lippincott-Rabin, Philadelphia, pp 47-57 